\title{
Neuropathologic features in the hippocampus and cerebellum of three older men with fragile $X$ syndrome
}

Claudia M Greco ${ }^{1,3}$, Celestine S Navarro ${ }^{7}$, Michael R Hunsaker ${ }^{4,5}$, Izumi Maezawa ${ }^{3}$, John F Shuler ${ }^{7}$, Flora Tassone ${ }^{1,7}$, Mary Delany ${ }^{8}$, Jacky W Au ${ }^{1,2}$, Robert F Berman ${ }^{4,5,6}$, Lee-Way Jin ${ }^{1,3}$, Cynthia Schumann ${ }^{1,9}$, Paul J Hagerman ${ }^{6,7}$, Randi J Hagerman ${ }^{1,2,6^{*}}$

\begin{abstract}
Background: Fragile $X$ syndrome (FXS) is the most common inherited form of intellectual disability, and is the most common single-gene disorder known to be associated with autism. Despite recent advances in functional neuroimaging and our understanding of the molecular pathogenesis, only limited neuropathologic information on FXS is available.

Methods: Neuropathologic examinations were performed on post-mortem brain tissue from three older men (aged 57, 64 and 78 years) who had received a clinical or genetic diagnosis of FXS. In each case, physical and cognitive features were typical of FXS, and one man was also diagnosed with autism. Guided by reports of clinical and neuroimaging abnormalities of the limbic system and cerebellum of individuals with FXS, the current analysis focused on neuropathologic features present in the hippocampus and the cerebellar vermis.

Results: Histologic and immunologic staining revealed abnormalities in both the hippocampus and cerebellar vermis. Focal thickening of hippocampal CA1 and irregularities in the appearance of the dentate gyrus were identified. All lobules of the cerebellar vermis and the lateral cortex of the posterior lobe of the cerebellum had decreased numbers of Purkinje cells, which were occasionally misplaced, and often lacked proper orientation. There were mild, albeit excessive, undulations of the internal granular cell layer, with patchy foliar white matter axonal and astrocytic abnormalities. Quantitative analysis documented panfoliar atrophy of both the anterior and posterior lobes of the vermis, with preferential atrophy of the posterior lobule (VI to VII) compared with age-matched normal controls.
\end{abstract}

Conclusions: Significant morphologic changes in the hippocampus and cerebellum in three adult men with FXS were identified. This pattern of pathologic features supports the idea that primary defects in neuronal migration, neurogenesis and aging may underlie the neuropathology reported in FXS.

\section{Background}

Fragile X syndrome (FXS) is the most common inherited form of intellectual disability, and the fragile $\mathrm{X}$ mental retardation 1 (FMR1) gene is the most common single-gene mutation associated with autism [1-5]. Approximately $30 \%$ of individuals with FXS meet all criteria of the Diagnostic and Statistical Manual of

\footnotetext{
* Correspondence: randi.hagerman@ucdmc.ucdavis.edu

${ }^{1}$ MIND Institute, University of California-Davis Medical Center, Sacramento, CA, USA

Full list of author information is available at the end of the article
}

Mental Disorders, Fourth Version (DSM IV) criteria for autism as assessed with standardized measures (Autism Diagnostic Observation Schedule (ADOS) and Autism Diagnostic Interview, Revised: ADI-R (ADI-R)), and an additional $30 \%$ of those with FXS have PDD NOS (pervasive developmental disorder, not otherwise specified) [6].

The FMR1 protein (FMRP) is absent or deficient in individuals with FXS. FMRP is an RNA-binding protein that regulates the translation of a number of mRNAs whose protein products are important for synaptic

\section{() Biomed Central}


development, maintenance and plasticity. In the absence of FMRP, production of many synaptic proteins are dysregulated, such as postsynaptic density protein (PSD)95, Arc (Arg 3.1), matrix metalloproteinase (MMP)9, the $\alpha$ amino-3-hydroxyl-5-methyl-4-isoxazole-propionate (AMPA) receptor subunits, glutamate receptor (GluR)1 and GluR2, and $\mathrm{Ca}^{2+} /$ calmodulin-dependent protein kinase (CaMK)II [7-9]. Other proteins regulated by FMRP are involved with axon guidance and cell motility, including microtubule-associated protein (MAP) $1 \mathrm{~B}$ and Semaphorin 3F, suggesting that dysregulation of these proteins in the absence of FMRP may be related to the periventricular heterotopia previously reported in some cases of FXS [10-13]. Furthermore, FMRP interacts with several proteins that have been identified as potential candidate genes underlying a number of neurodevelopmental disorders, such as the neuroligin family, neurorexin 1, SH3 and multiple ankyrin repeat domains (SHANK 3), phosphatase and tensin homolog (PTEN), mammalian target of rapamycin (mTOR), PSD95, Wnt7a and Arc (Arg 3.1) [7,14-20]. A recent report by Luo et al. [20] demonstrated that FMRP in the mouse regulates the protein expression of several components crucial for adult neurogenesis, including cyclindependent kinase (CDK)4, cyclin D1 and glycogen synthase kinase (GSK) $3 \beta$. Dysregulation of GSK3 $\beta$ leads to reduced Wnt signaling pathway activity, which alters the expression of neurogenin 1 and the fate specification of adult neuroprogenitor cells.

Despite recent advances in our understanding of the molecular pathology underlying FXS, only limited neuropathologic information is available (Table 1). To address this issue, we analyzed the hippocampus and cerebellum in three men with FXS using histologic, immunochemical and molecular techniques. Neuropathologic abnormalities were evident in both the hippocampus and the cerebellum of all three cases. The CA1 region of the hippocampus showed local thickening and abnormal undulations, and appeared to be enlarged relative to age-matched, non-FXS control hippocampi. The cerebellum, particularly lobules VI to VII of the vermis, was reduced in size and displayed reduced Purkinje cell (PC) density compared with age-matched, non-FXS controls. These findings correspond to previously reported studies of individuals with FXS using magnetic resonance imaging (MRI), in which dysmorphic, enlarged hippocampi, decreased cerebellar size, and preferential atrophy of vermal lobules VI to VII were observed [21-23].

\section{Case histories}

\section{Patient 1}

This man was the product of a full-term pregnancy. He had global developmental delay, and was admitted to a residential facility at 15 years of age, because of difficulties with aggression. He was diagnosed with FXS aged 52 years; the findings of the physical examination included large prominent ears, a long narrow face and macroorchidism. At this time, he had a full-scale intelligence quotient (FSIQ) of 34, which had fallen to 22 at the age of 65 years. A chromosomal analysis at 52 years of age yielded $23 \%$ fragile X-positive metaphases.

The patient was a social individual, who befriended his caretakers and peers. He repeated words and phrases, and required no psychotropic medications. Over time, he developed high blood pressure, prostate cancer and osteoporosis, and a seizure disorder at 75 years that required treatment with phenytoin. At the age of 77 years, he was diagnosed with gait ataxia and began treatment with amantadine, without therapeutic benefit. Computed tomography (CT) of the brain revealed cerebral and cerebellar atrophy and ischemic white-matter changes. Within the last six months of his life, the patient was diagnosed with dementia, chronic obstructive pulmonary disease and a left bundle branch block. At 78 years, he presented to the hospital with abdominal pain and 'coffee-ground' emesis, and died within 24 hours of admission. Genomic analysis of DNA isolated from post-mortem brain tissue established his full mutation status, with hypermethylated, full mutation alleles (CGG repeats of 339, 486, 619, 755, 938, 1225).

\section{Patient 2}

This man was the product of a normal pregnancy. $\mathrm{He}$ had developmental delay in early childhood, and had severe language deficits; he was never able to speak in full sentences. He was hyperactive and anxious throughout childhood, and showed excessive rocking, handflapping, poor eye contact, tactile defensiveness and destructive tantrums, resulting in a diagnosis of autism. He entered a group home at 30 years of age, where he required antipsychotic medications for behavior problems.

On physical examination, he was found to have mitral valve prolapse. The family history included a brother with FXS, and a sister who was a fragile $\mathrm{X}$ premutation carrier and mother of two daughters with FXS. The patient's mother had had severe depression in her 40s, developed unsteady writing and dementia in her 80 s, and was still alive at 94 years at the time of this patient's death. The patient died at the age of 57 years despite resuscitative efforts after choking on food. Molecular testing on postmortem brain tissue demonstrated the presence of a full mutation allele (436 CGG repeats).

\section{Patient 3}

This man was born after a normal pregnancy, and had delayed development. His physical features included a 
Table 1 Documented neuropathology in previously published studies

\begin{tabular}{|c|c|c|c|c|c|}
\hline Author & Patient & Tissues & $\begin{array}{l}\text { Brain region } \\
\text { analyzed }\end{array}$ & $\begin{array}{l}\text { Method of } \\
\text { analysis }\end{array}$ & Microscopical neuropathology \\
\hline $\begin{array}{l}\text { Dunn et al, } \\
1963[12]\end{array}$ & $\begin{array}{l}\text { 18-year-old man, later } \\
\text { diagnosed with fragile } \\
\text { X syndrome }\end{array}$ & $\begin{array}{l}\text { Brain: } 1040 \mathrm{~g}^{1} \text { normal } \\
\text { cortical pattern, mild } \\
\text { ventricular dilatation }\end{array}$ & $\begin{array}{l}\text { Multiple } \\
\text { regions }\end{array}$ & $\mathrm{LM}^{2}$ & $\begin{array}{l}\text { Inc neurons in subcortical white matter; reduced } \\
\text { myelin in cerebral white matter; siderosis of } \\
\text { globus pallidus, inferior olivary heterotopia, }\end{array}$ \\
\hline $\begin{array}{l}\text { Rudelli et al, } \\
1983 \text { [59] }\end{array}$ & 23-, 24-week fetuses & $\begin{array}{l}\text { Brains(2) showing } \\
\text { normal cortical } \\
\text { development; testes }\end{array}$ & & $\begin{array}{l}\text { Gross } \\
\text { examination } \\
\text { only }\end{array}$ & None noted \\
\hline $\begin{array}{l}\text { Rudelli et al, } \\
1985 \text { [60] }\end{array}$ & 62-year-old male & $\begin{array}{l}\text { Brain: mild cortical } \\
\text { atrophy }\end{array}$ & $\begin{array}{l}\text { Parieto- } \\
\text { occipital } \\
\text { neocortex }\end{array}$ & LM, Golgi, EM ${ }^{3}$ & $\begin{array}{l}\text { Increased long, thin, immature spines; decreased } \\
\text { synaptic length by EM }\end{array}$ \\
\hline $\begin{array}{l}\text { Desai et al, } \\
1990[13]\end{array}$ & $\begin{array}{l}\text { 33-year-old male with } \\
\text { ALS }^{4}\end{array}$ & $\begin{array}{l}\text { Brain }(1850 \mathrm{~g}) \text { with ALS } \\
\text { pathology; testes }\end{array}$ & Whole brain & LM & $\begin{array}{l}\text { Heterotopia of olivary nucleus; Subcortical white } \\
\text { matter neuronal clusters }\end{array}$ \\
\hline \multirow[t]{2}{*}{$\begin{array}{l}\text { Hinton et al, } \\
1991[61]\end{array}$} & $\begin{array}{l}\text { 15-, 41-, 62-year-old } \\
\text { male patients (62-year- } \\
\text { old in Rudelli, } 1985 \\
[60])\end{array}$ & Brains (3):normal & $\begin{array}{l}\text { Parieto- } \\
\text { occipital } \\
\text { neocortex }\end{array}$ & Golgi & Increased long, thin spines \\
\hline & & & $\begin{array}{l}\text { Cingulate, } \\
\text { temporal } \\
\text { association } \\
\text { cortex }\end{array}$ & $\begin{array}{l}\text { Morphometric } \\
\text { analysis }\end{array}$ & No significant differences in neuronal counts \\
\hline $\begin{array}{l}\text { Wisniewski, } \\
1991[62]\end{array}$ & 63-year-old man & $\begin{array}{l}\text { Brain: mild atrophy, } \\
\text { hydrocephalus, } \text { AVM }^{5} \text { of } \\
\text { left temporal lobe }\end{array}$ & $\begin{array}{l}\text { Unspecified } \\
\text { neocortex }\end{array}$ & Golgi & Increased long, thin spines \\
\hline $\begin{array}{l}\text { Sabaratnam, } \\
2000[63]\end{array}$ & 67-, 87-year-old men & $\begin{array}{l}67-y e a r \text { old }(1778 \mathrm{~g}) .87- \\
\text { year-old: brain enlarged, } \\
\text { ventricular dilatation }\end{array}$ & $\begin{array}{l}\text { 87-year-old: } \\
\text { hippocampus, } \\
\text { cerebellum }\end{array}$ & LM & $\begin{array}{l}\text { CA4 cell loss, gliosis; } \text { PC }^{6} \text { dropout, Bergmann } \\
\text { gliosis }\end{array}$ \\
\hline $\begin{array}{l}\text { Irwin et al, } \\
2001[64]\end{array}$ & $\begin{array}{l}\text { 48-, 48-, 73-year-old } \\
\text { men }\end{array}$ & Brain & $\begin{array}{l}\text { Temporal and } \\
\text { visual } \\
\text { neocortex }\end{array}$ & Golgi & $\begin{array}{l}\text { Increased long, thin spines; increase in spine } \\
\text { density }\end{array}$ \\
\hline $\begin{array}{l}\text { Moro et al, } \\
2006[11]\end{array}$ & $\begin{array}{l}\text { 4.5-year-old and } \\
\text { 13-year-old boys }\end{array}$ & Live patients & & $\left.M R\right|^{7}$ & Periventricular heterotopias in both cases \\
\hline
\end{tabular}

${ }^{1}$ Brain weights within normal limits unless otherwise noted.

${ }^{2}$ Light microscopy, standard histologic stains.

${ }^{3}$ Electron microscopy.

${ }^{4}$ Amyotrophic lateral sclerosis.

${ }^{5}$ Arteriovenous malformation.

${ }^{6}$ Purkinje cell.

${ }^{7}$ Magnetic resonance imaging.

long face, prominent ears and macroorchidism. Abnormal behavioral features included anxiety and handbiting. The patient was shy but interactive, and he was able to speak in full sentences. He had savant skills for trivia, and he had an FSIQ of 57 in adulthood. He lived in a group home, and was productively employed.

In his fifties, the patient showed increased anxiety and increased self-abusive behaviors, and he became increasingly rigid in his routines. He developed hypothyroidism that required levothyroxine, and hyperlipidemia that was treated with simvastatin. At the age of 64 years, the patient developed pain in his abdomen, was diagnosed with a primary liver neoplasm, and died within 3 months without a definitive tumor-tissue diagnosis. Southern blot analysis of DNA isolated from post-mortem brain tissue showed methylation mosaicism, with a hypermethylated, full mutation allele (429 CGG repeats) present in approximately $72 \%$ of the cells, with the remaining alleles unmethylated, and ranging from approximately 340 to 440 CGG repeats.

\section{Methods \\ Pathology \\ Autopsies}

Brain autopsies were performed in accordance with protocols approved by the University of California-Davis institutional review board and informed consent was obtained from family members.

One hemisphere of the fresh brain was cut into coronal blocks $10 \mathrm{~mm}$ thick, and frozen at $-80^{\circ} \mathrm{C}$; the remaining hemisphere was fixed in $10 \%$ phosphatebuffered formalin. The temporal lobe was separated from the fixed hemisphere, and serially sectioned into blocks $5 \mathrm{~mm}$ thick for serial embedding of the 
amygdaloid-hippocampal complex. The blocks were embedded in paraffin wax and cut into serial sections $5 \mu \mathrm{m}$ thick. The brainstem was separated from the cerebrum at the level of the midbrain. The cerebrum was coronally sectioned, the brainstem was sectioned in the perpendicular plane, and the cerebellum was cut into sagittal blocks $5 \mathrm{~mm}$ thick. The blocks were embedded in paraffin wax and cut into serial sections $5 \mu \mathrm{m}$ thick. Brain sections were inspected grossly for abnormalities. Sampling for paraffin-wax embedding was performed for each case as follows: serial sections of the hippocampal complex, midline samples of each of the three vermal lobules, and one section of the lateral posterior lobe of the cerebellar cortex.

Matched samples were taken from five neurologically normal controls matched for age and gender (mean \pm SD, $70 \pm 9$ years, range 60-8) obtained from the autopsy tissue repository at the University of California, Davis Medical Center Department of Pathology. Fixation, sampling, processing and staining were equivalent for control and FXS brains. Post-mortem intervals (PMIs) were, on average, considerably shorter for the FXS brains than for controls (FXS $16.3 \pm 4.4$ hours, range 11.5-20 hours; controls $52.0 \pm 43.6$ hours, range 12.5-119 hours).

For the purposes of this study, the vermal lobules of the cerebellum are referenced as follows: the superior lobule (lobules I to $\mathrm{V}$ of the anterior lobe of the cerebellum), and the posterior (lobules VI to VII) and inferior lobule (lobules VIII to X) of the posterior lobe of the cerebellum.

\section{Histology and immunochemistry}

All tissue blocks were processed for paraffin-wax embedding, histochemical staining and immunohistochemistry using previously reported techniques [24]. All histologic, immunohistochemical and counting techniques were performed on $5 \mu \mathrm{m}$ thick wax-embedded sections, as previously reported [24]. Briefly, tissue blocks were processed for paraffin-wax embedding using standard techniques. Staining was performed according to standard methods, using hematoxylin and eosin (H\&E) and Luxol fast blue (LFB) counterstained with periodicacid-Schiff (PAS) (for myelin). Silver (modified Bielschowsky) stain for axons was then used on selected cases [24]. Immunohistochemical staining using antiubiquitin, anti-glial fibrillary acidic protein (anti-GFAP), anti-CD68 (KP-1; Dako, Carpenteria, CA, USA), antileucocyte common antigen (LCA/CD-45; DakoCytomation, Glostrup Denmark) and anti-neurofilament (NF) (Dako) antibodies was performed using methods reported previously [24]. Dual-label (myelin basic protein (MBP)/ubiquitin) immunohistochemistry was performed using the avidin-biotin procedure, with antiMBP antibody (SM 194; Sternberger Monoclonals, Baltimore, MD, USA) visualized with diaminobenzidine and anti-ubiquitin antibody (Dako, Glostrup, Denmark) visualized with Nova Red (Vector Laboratories, Burlingame, CA, USA). Appropriate positive and negative controls were employed for each antibody.

\section{Immunofluorescent staining for calbindin}

Wax-embedded sections $5 \mu \mathrm{m}$ thick were dewaxed and blocked in $10 \%$ goat serum (Zymed, San Francisco, CA, USA) with $0.5 \%$ Triton X-100 for 1 hour, followed by $1 \%$ non-fat dry milk with $0.1 \%$ Triton X-100 for 30 minutes at room temperature. Sections were then incubated with 1:150 anti-calbindin antibody (Chemicon, Billerica, MA USA) diluted in $1 \%$ bovine serum albumin with $0.1 \%$ Triton $\mathrm{X}-100$ at $4^{\circ} \mathrm{C}$ for 48 hours, followed by the secondary antibody, 1:600 rabbit anti-IgG conjugated with Alexa 568 (Molecular Probes, Carlsbad, CA USA) for 1 hour at room temperature. Sections were then counterstained with 4',6-diamidino-2-phenylindole (Vector Laboratories), observed under a microscope (Eclipse E600, Nikon, Melville, NY, USA) and digitally photographed (SPOT RTke; SPOT Diagnostics, Sterling Heights, MI USA).

\section{Estimation of PC density in the cerebellum}

Owing to the advanced age of the three patients with FXS (57, 64 and 78 years) included in the present study, and to reports of reductions in PC number with normative aging, counts of the number of PCs in the three cases of FXS were compared with corresponding counts in the five age-matched non-FXS cerebella. The areas evaluated for PC number were from the superior, posterior and inferior vermal lobules, and one section of the lateral posterior lobe cerebellar cortex, stained for $\mathrm{H} \& \mathrm{E}$. In all cases, the portions of the lobules to be analyzed were marked on the slide before any microscopic analysis to reduce bias in selection of regions of interest (ROI), and the experimenter was blinded to the origin of the tissue sample (that is, which lobule was on which slide).

PCs were counted within defined ROI in the cerebellum using computer software to outline the ROI and then randomly select PCs for counting within the ROI (StereoInvestigator, version 8.0; Microbrightfield Inc., Williston, VT, USA). Briefly, at $4 \times$ magnification the PC layer (PCL) was outlined, taking care to not include the molecular or internal granular cell (IGL) layers. Tracing of ROI was completed for each of three $5 \mu \mathrm{m}$ thick serial sections, separated by $25 \mu \mathrm{m}$. The program was then used to cast a regularly spaced counting grid over the traced ROI, and individual $25 \times 25 \mu \mathrm{m}$ counting frames were defined within each grid. PCs within each of 100 counting frames were then counted at $400 \times$ magnification (E-600 microscope, Nikon). PCs were identified morphologically, and PC nuclei rather than nucleoli were counted, as nucleoli in the PC do not stain reliably [25]. Any PC nuclei falling within or contacting the 
inclusion zones of each counting frame were counted, whereas any nuclei contacting the exclusion zones were not counted. After all counting frames were evaluated, the linear length (in $\mathrm{mm}$ ) of the PC layer was measured and recorded. The number of PCs in the PCL and the linear length of the PCL were used to calculate the number of PC per mm as described previously [25].

The limited quantity of tissue available (three sections as opposed to a full serial set through the cerebellum) prevented a stereologic estimate of total PC numbers. Therefore, data are presented as the mean number of PCs counted per millimeter length of the PCL (that is, a density measurement [25]). In this way, we strove to be as conservative as possible to ensure that any reduction in PC number in FXS found would be underestimated rather than overestimated.

Additionally, as there have been reports of decreased cerebellar size in FXS [21], foliar cross-sectional width was measured at $20 \times$ magnification using the 'quick measure' line function on the StereoInvestigator software. These measurements were routinely taken at the midpoint of the folia to standardize the relative location of the measurements. Each measurement was taken thee times, and the average of the three measurements is reported. Additionally, each section was evaluated twice on separate days using the same procedures, and similar results were obtained.

\section{Molecular measures}

Genomic DNA was isolated from $500 \mathrm{mg}$ of frozen cortex and cerebellum from the three patients with FXS using standard methods (Qiagen, Valencia, CA, USA). In two cases (patients 2 and 3), DNA was also extracted from whole blood (3 to $5 \mathrm{ml}$ ); results (CGG repeat sizes) were consistent with those obtained in brain tissue. CGG repeat size and methylation status were determined using both PCR and Southern Blot analysis using an image detection system (FluorChem 8800; Alpha Innotech, San Diego, CA, USA) as previously described [26]. For Southern blot analysis, $10 \mu \mathrm{g}$ of DNA were digested with EcoRI and NruI, and the Stb12.3 FMR1 genomic sequence, labeled with Dig-11-dUTP, was used as a probe. Genomic DNA was also amplified by PCR using the ' $\mathrm{c}$ ' and ' $\mathrm{f}$ ' primers described by Tassone et al. [26].

\section{Results \\ Pathology \\ Gross examination}

The cerebrums of patients 1 and 3 were grossly normal, with mild cortical atrophy deemed appropriate for age. Patient 2 had moderate ventricular dilatation, and prominent atrophy of the hippocampus and amygdala. The cerebella of all three cases appeared generally decreased in size. On midline sagittal sectioning through the vermis, both the superior and posterior lobar divisions were atrophied compared with age-matched control brains. Of the three patients, only patient 2 showed preferential atrophy of the posterior lobule by visual inspection. The inferior lobule appeared the least atrophied of the vermal lobules in all three patients. Sagittal sections of the lateral posterior lobe cortex from all patients showed no obvious atrophy upon visual inspection.

\section{Microscopic examination}

Hippocampus Because the structural features of the CA1/Sommer sector of the hippocampus were overshadowed by ischemic changes in patient 2 , we limited our analysis of hippocampal microscopic structure to patients 1 and 3 . In both cases, in several sections throughout the hippocampus evaluated, CA1 had similar abnormalities in the microanatomic organization of the pyramidal cell layer. There was a bulge or expansion composed of increased numbers of pyramidal cells (Figure 1) arranged in an undulating pattern. In neighboring regions, there appeared to be a reduction in pyramidal cell number. In all three cases, the penetrating cortical arterioles of the temporal cortex showed vascular hyalinosis. These vessel walls were negative for amyloid birefringence with Congo red stain, and showed faint staining with $ß$-amyloid antibody (not shown). Immunostaining was negative in brain parenchyma for $\beta$-amyloid, $\alpha$-synuclein, ubiquitin and tau, stains that are routinely used for the neuropathologic diagnosis of the most commonly occurring neurodegenerative disorders, such as Alzheimer's disease, Lewy Body disease and frontotemporal dementia.

Cerebellum Histopathologic abnormalities identified by $H \& E$ stain in the vermal lobules and the lateral posterior cerebellar cortex were similar in all three patients. Prominent, patchy loss of PC could be visualized with either H\&E or calbindin stains. Quantitative analyses revealed a decrease of more than $40 \%$ in the number of PC (Figure 2) in all vermal lobules and lateral cortical sections compared with age-matched controls. Existing PCs were frequently clustered, and within these small groups, often lacked proper orientation. Compared with age-matched normal controls, there were increased numbers of PC in the IGL. Bergmann glia were present in expected numbers, and showed no increase in cytoplasmic staining for GFAP, contrary to what would be expected in Bergmann gliosis. There were small numbers of scattered GFAP-positive astrocytes in folia that demonstrated mildly expanded cytoplasmic borders; however, these changes fell short of those seen with either reactive or gemistocytic astrocytic morphology. Vellate astrocytes of the IGL showed no changes on GFAP immunostaining. Myelin staining (LFB-PAS) showed mild patchy pallor, most often in distal foliar white matter. NF staining revealed foci of scattered, 


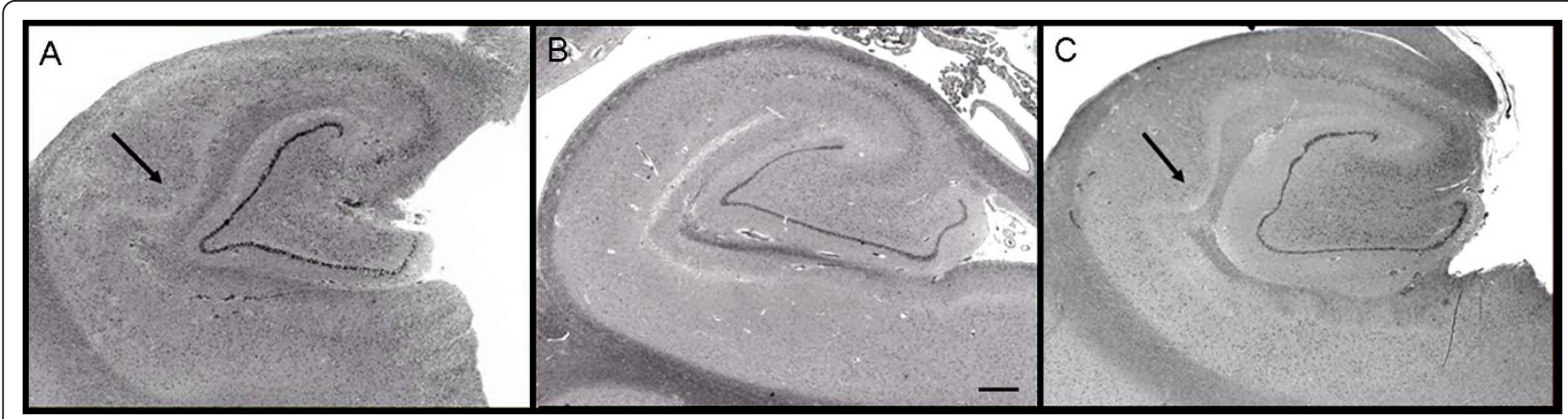

Figure 1 Hippocampal formation. Images of the hippocampal formation at the level of the lateral geniculate body from (A) patient 1 and (C) patient 3 show abnormal expansion of CA1 by increased numbers of pyramidal neurons. These are compared with the more usual hippocampal microarchitecture that shows a thinner linear band of neurons in CA1, as seen in (B) a 62-year-old male control. Haematoxylin and eosin, original magnification $\times 10$; scale bar $=1 \mathrm{~mm}$. Arrow indicates bulge/expansion composed of increased numbers of pyramidal cells in (A) patient 1 and (C) patient 3.

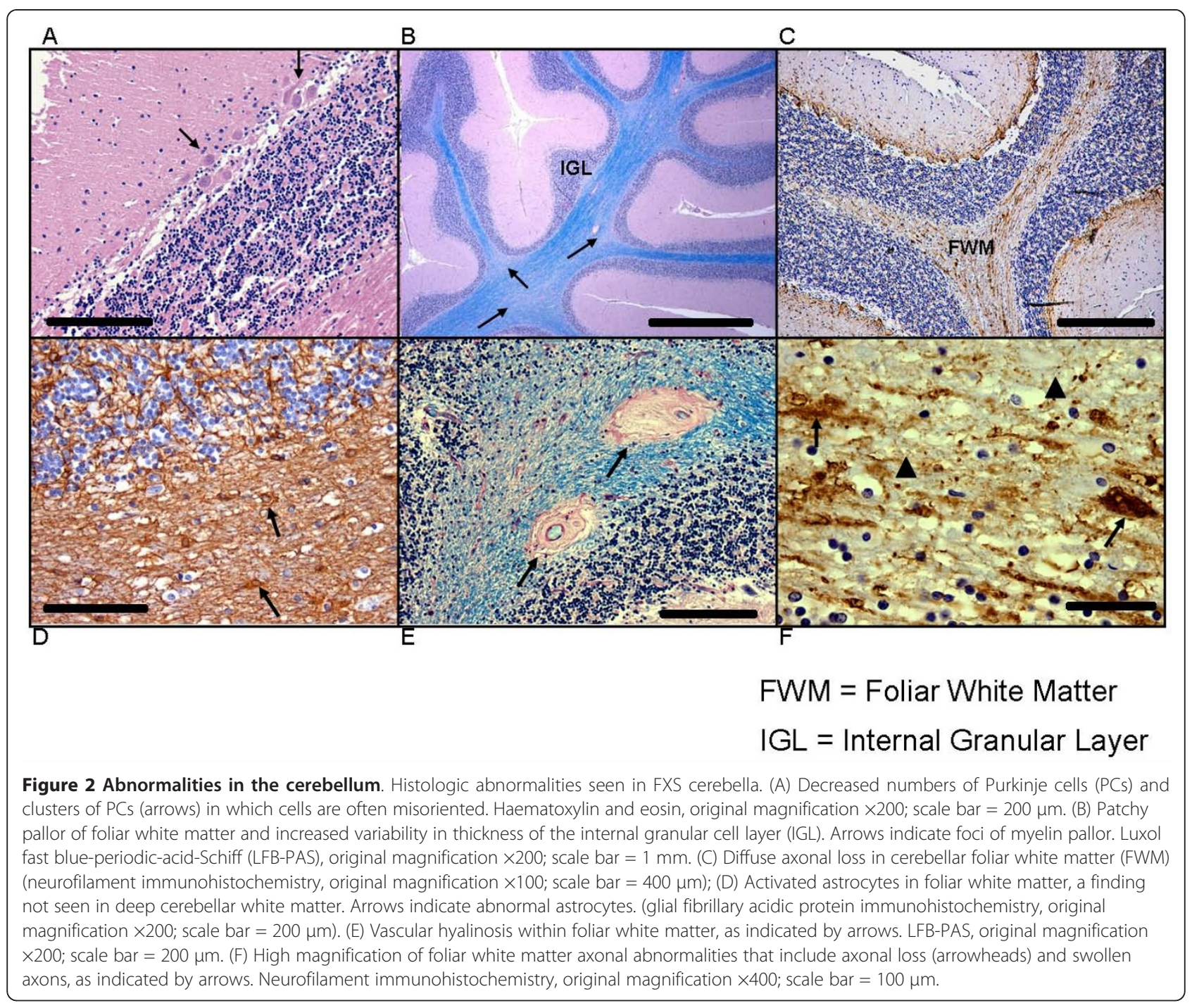


swollen and fractured axons that corresponded to regions of myelin pallor. Within the distal foliar white matter, there were scattered white-matter small vessels with prominent hyalinosis of their walls, which were not seen in controls.

Based on the improved characteristics of calbindin antibody staining over standard Nissl stains as a marker for PCs in postmortem human brains [25], we used calbindin immunofluorescence (IF) to evaluate the morphology of PCs and to confirm any reductions in cell number identified in $\mathrm{H} \& \mathrm{E}$-stained cerebella. In agematched controls (Figure 3), calbindin-immunoreactive PCs were spaced regularly, although somewhat variably, depending on the plane of the section, and the dendrites of control PCs had fine processes from their dendritic trees. By contrast, the three patients had a substantial reduction in calbindin-immunoreactive $\mathrm{PCs}$, with attenuation of dendritic arborization. Similar features were seen throughout the vermis and lateral cortex.

\section{$P C$ density in the cerebellum}

Based on the cell-density measurements performed in the present study, there was a $52 \%$ reduction in PCs per $\mathrm{mm}$ in the superior lobule, a $54 \%$ reduction in the posterior lobule, a $49 \%$ reduction in the inferior lobule and a $58 \%$ reduction in the lateral cortex sample, compared with control cerebellar sections. There was no numerical overlap between counts of PCs between the cases and controls; all patients with FXS had clear reductions in $\mathrm{PC}$ density in all cerebellar regions evaluated (Figure 4A-D). These results suggest a global

A
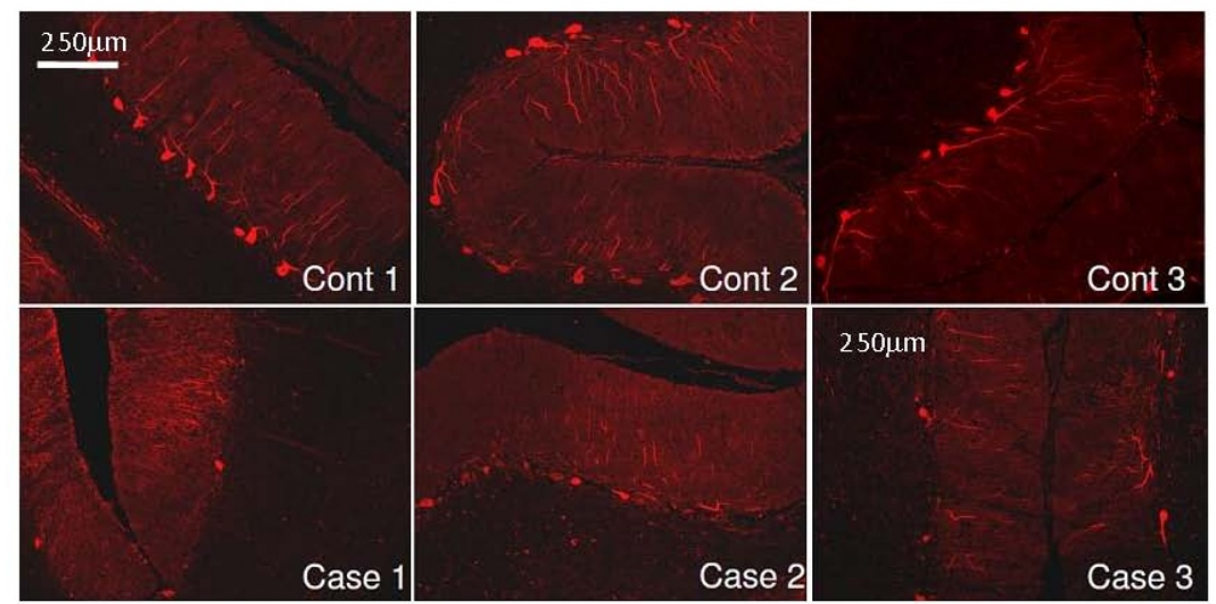

B
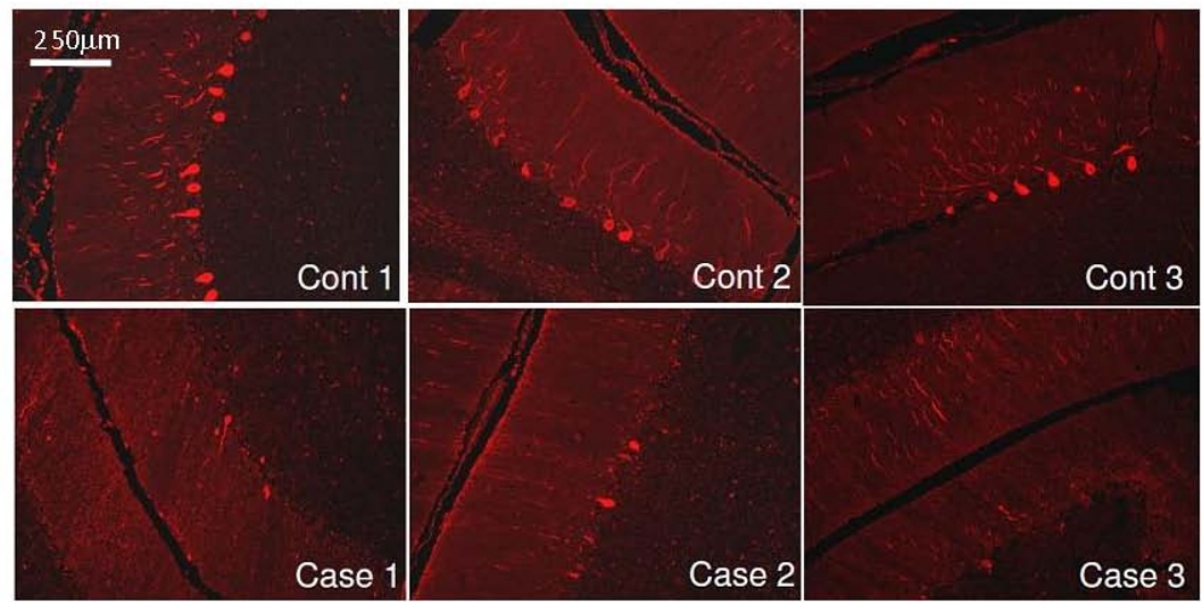

Figure 3 Calbindin immunofluorescent staining in the cerebellar cortex. Calbindin immunofluorescent staining of the cerebellar cortex indicates decreased numbers of PCs and diminished complexity of the PC dendritic arborization compared with age-matched controls. Similar changes were observed in all vermal lobules and in lateral posterior lobe cortex. (A) Vermal inferior lobule and (B) lateral posterior lobe cerebellar cortex. Original magnification $\times 10$; scale bar $=250 \mu \mathrm{m}$. 


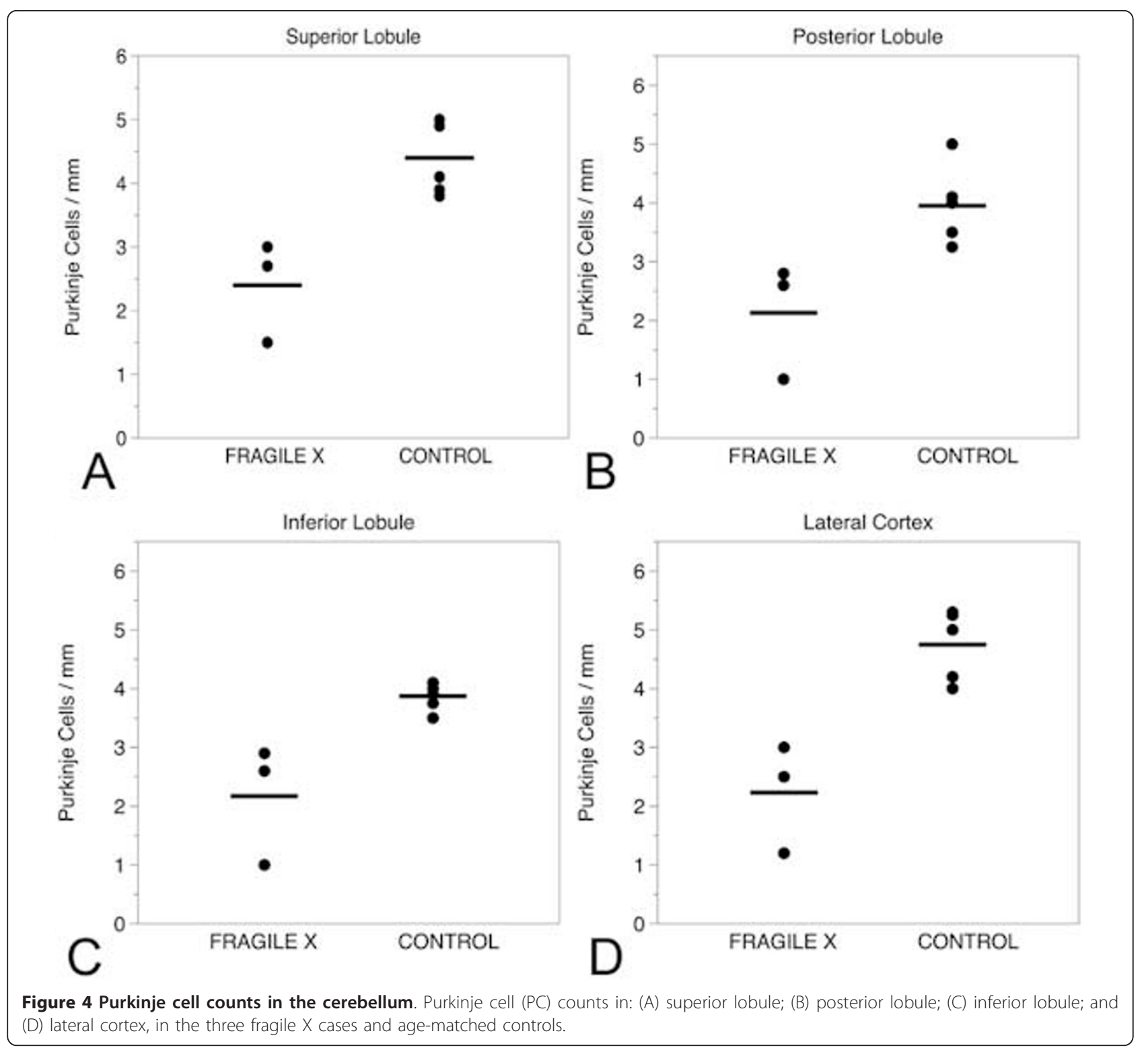

reduction in PC number in the patients with FXS relative to the age-matched non-FXS controls. This reduction in PC number was supported by the calbindin IF results.

To further study possible microscopic correlates to previously observed MRI abnormalities in the cerebellar vermis in FXS, we obtained simple measurements of foliar width. There were no dramatic reductions in foliar widths in the superior and inferior vermal lobules $(0 \%$ and $7 \%$ reduction, respectively, relative to controls); visual inspection of this data revealed a large overlap in foliar widths between cases with FXS and controls (Figure $5 \mathrm{~A}-\mathrm{D})$. However, there was a dramatic reduction in foliar width in the posterior lobules ( $21 \%$ reduction) and in the lateral cortex of the cerebellum (20\% reduction) compared with controls. Foliar width measurements of the inferior lobules gave similar values to controls for patients 1 and 3. Patient 2 also had reduced foliar width in the inferior lobule, (Figure 5C). There was no numerical overlap between patients with FXS and controls; all cases with FXS had clearly reduced foliar widths in the lateral cortex and the posterior lobule compared with all of the controls evaluated. These data suggest that lobules VI to VII are decreased in size in FXS compared with non-FXS controls, but that lobules I to V and VIII to $\mathrm{X}$ appear to be the same size as non-FXS controls, consistent with published MRI findings, which identified a similar pattern. 


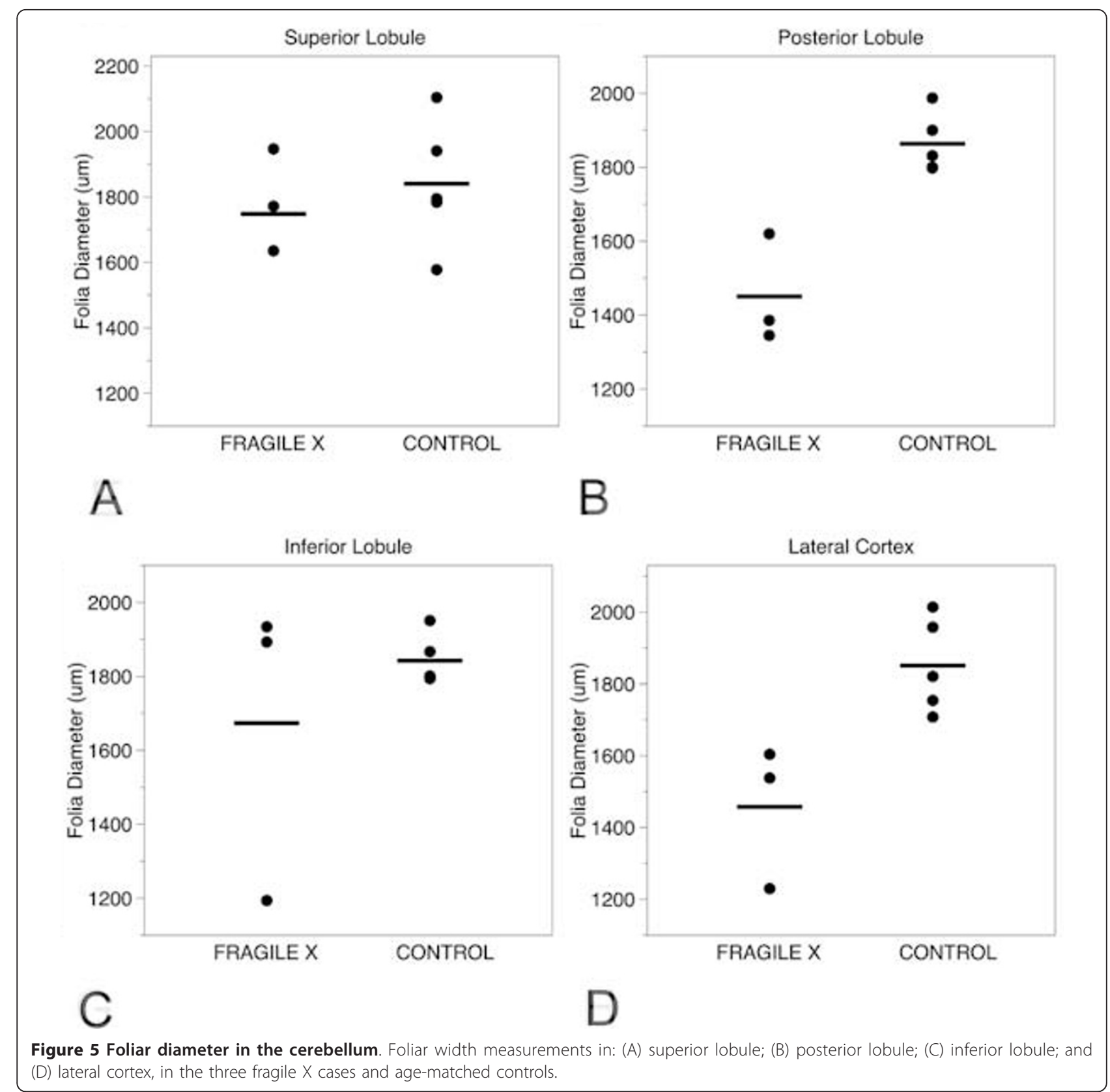

\section{Discussion}

We have identified novel microscopic abnormalities in the hippocampal formation and cerebellar vermis in three aged men with FXS. These offer correlations with established MRI changes in these structures in individuals with FXS. Neuroimaging studies of FXS have shown enlargement of the hippocampi $[21,22,27,28]$ and decreased cerebellar size, particularly the posterior lobe of the cerebellum. In patients 1 and 3, the CA1 pyramidal cell layer of the hippocampus was focally enlarged and widened (Figure 1). Such microscopic malformations of the hippocampus have rarely been identified in the medical literature. 'Tectonic hippocampal malformation', described to date only in temporal lobe epilepsy [29], appear similar to the hippocampal pathology we found. It is likely that this finding in FXS may be related to abnormalities in adult neurogenesis, as FMRP deficiency has been reported to increase the early proliferation of both stem and progenitor cells in addition to reducing the survival rate of young neurons [20]. In addition, the loss of FMRP down-regulates the Wnt pathway, which is important for cell proliferation in the hippocampus [20]. Therefore, focal proliferation adjacent to focal cell loss, representing a focal dysplasia, 
may be related to the dysregulation of a number of proteins in the absence of FMRP. The dysregulation of the Wnt pathway in the absence of FMRP also relates to dysregulated neural migration that appears to underlie some neuropathologic features of FXS [11].

The first neuroanatomical abnormality in FXS visualized by MRI was the decreased size of the posterior lobe of the cerebellar vermis [30]. Using MRI, Gothelf et al. [23] studied 84 children with FXS who ranged in age from 1.1 to 22.7 years (range $11.7 \pm 5.7$ ) and 72 age-matched controls, and found that size of the posterior lobe of the vermis (lobules VI to X) correlated positively with FSIQ and FMRP levels. Particular atrophy of lobules VI to VII of the vermis on MRI has also been described $[23,30]$. Our measurements of foliar width support these previous studies by demonstrating decreased width of the folia in the posterior lobule compared with the adjacent superior and inferior lobules. We have also identified a $40 \%$ reduction in PCs in the vermis and in a limited analysis of the cortex of the lateral posterior lobe. In all areas of cerebellum examined, there was disorientation and misplacement of PC, mild conformational changes in the microscopic appearance of the IGL, and axonal and myelin pathology in the foliar white matter.

Decreased cerebellar vermis size is a common finding in other neurodevelopmental disorders, including attention deficit hyperactivity disorder (ADHD), autism, 22q11.2 deletion syndrome (velocardiofacial syndrome), Joubert syndrome and schizophrenia [31-36]. Additionally, PC count is reduced in some cases of autism [25,36-38], and PC size is reduced in schizophrenia $[39,40]$. In addition to a reported negative correlation between vermis volume and autistic tendencies in both autism and FXS $[38,41]$, it is suggested that the vermis may modulate emotion in schizophrenia, and underlie some of the pathogenesis behind the disease [39]. Hessl et al. [27] suggested that a subset of behavioral irregularities seen in FXS, such as perseverative speech, hyperactivity, tactile defensiveness, language dysfunction and attention deficits, could be related to improper functioning of the cerebellar vermis.

Studies on schizophrenia and autism have also revealed features in the hippocampal formation and cerebellum consistent with migration disorders. Heterotopic displacement and aberrantly clustered neurons, particularly pre-alpha cells, in laminae II and III have been reported in the schizophrenic entorhinal cortex [42-44]. Owing to the interconnections of the entorhinal cortex and hippocampus, and its connections to other cortical areas, such migration abnormalities could contribute significantly to the neuropsychologic deficits in schizophrenia [42]. Cases of autism have been reported in which heterotopic cells were observed in the cerebellar molecular layer [37], in the white matter of the anterior cingulate gyrus and inferior frontal gyrus, in the hippocampus, the wall of the lateral ventricle [45] and lateral to the olivary bodies [46]. However, these findings in autism are limited because of a dearth of available tissue. In addition, conflicting evidence has arisen from other studies attempting to replicate the findings in schizophrenia [47-49]. It is interesting that a recent report of FMRP levels in neuropsychiatric disorders without an FMR1 mutation demonstrated very low levels of FMRP in the brains of people with schizophrenia [50] and people with autism [51]. Therefore, low levels of FMRP in both autism and schizophrenia would be likely to lead to an overlap or commonality of neuropathologic findings between these disorders and FXS.

The FMR1 gene has been implicated in neuronal migration anomalies [11]. Specifically, there have been previous observations of periventricular heterotopia in neuropathologic studies of FXS [12,13], and on magnetic resonance imaging (MRI) scans in two cases of FXS [11]. The absence of FMRP has been reported to dysregulate molecules involved in axon guidance and mobility, including Wnt 7a, semaphorin 3F and MAP1B, possibly leading to migration abnormalities similar to those we report here $[10,11,17,20]$. A recent study of the cytoplasmic FMR1 interacting protein (CYFIP1) bacterial artificial chromosome (BAC) transgenic mouse, which over-expresses CYFIP, demonstrated similar disorientation and misalignment of the PCs in addition to abnormalities of the dendritic tree detected by Golgi staining, similar to our findings with calbindin staining [52]. CYFIP is regulated by FMRP, and it is an interacting protein with FMRP that is crucial to the repression of proteins important for synaptic plasticity by FMRP [53]. Expression of CYFIP is dysregulated in FXS [54]. Further investigation is therefore warranted to elucidate prenatal or perinatal migratory mechanisms involved in FXS, autism and other neurodevelopmental disorders.

Our findings provide insight into the structural correlates that relate to functional deficits involving the cerebellum in FXS. The decreased density of PCs, which constitute the primary efferents from the cerebellar cortex, in these older men may be related to (or result from) abnormal GABAergic transmission and disrupted cortical-cerebellar connectivity $[55,56]$. The cerebellum is the site of termination of the spinocerebellar pathway, which carries subconscious proprioception [27]; and is thus involved in motor functions including the relation of external responses to a person's own acts, and the ability to expect the outcomes of particular movements, which are impaired in FXS [27]. A recent study of the medical and neurologic problems of aging in FXS in over 60 individuals demonstrated a high rate of motor problems including parkinsonian features of tremor and 
ataxia [57]. In addition, the recent report of the role of FMRP in neurogenesis has shown deficits in neurogenesis in cells with an absence of FMRP [20]. These findings may have significant effects on the aging process of those with FXS and should stimulate further neuropathologic studies in FXS.

\section{Conclusion}

Our neuropathologic analysis of post-mortem CNS tissue from three patients with FXS provides clear evidence of cytoarchitectural abnormalities of the aging brain in individuals with FXS. We speculate that these abnormalities may reflect defects in neuronal migration and neurogenesis, and neuronal function and maintenance in aging individuals [58]. Our results also reveal microscopic pathologic features in FXS brains that overlap with those reported in cases of autism and schizophrenia. These similarities suggest that shared pathogenic mechanisms may underlie these developmental disorders, and the recent reports of low FMRP in the brain of people who have died from schizophrenia or autism further supports this concept [50,51]. Additional neuropathologic studies may also identify a degenerative component that corresponds to the clinical neurologic deterioration often seen in individuals with FXS as they age [57]. The results from the current study warrant more comprehensive studies on a larger population of cases with FXS, which requires a coordinated effort in collecting and studying these brain samples. Our hope is that correlation of this information with molecular and clinical studies will increase our understanding of this and other genetic disorders, and result in early treatment that may diminish or nullify the developmental and aging effects of this genetic disorder.

\section{Acknowledgements}

This work was supported by the National Institute of Health $(\mathrm{NIH})$ grants HD036071, HD056031, NS044299, AG024488, HD02274, MH77554, MH078041, RL1 AG032115, RL1 NS062411 and RL1 AG032119, the National Fragile X Foundation and the MIND Institute. This publication was also made possible by a grant (UL1 DE019583) administered by the National Center of Dental and Craniofacial Research (NCDCR) and another grant (UL1 RR024146) from the National Center for Research Resources (NCRR), both of which are components of the NIH and NIH Roadmap for Medical Research, and a grant from the University of California Office of President to establish the University of California Pediatric Neuropathology Consortium (UCPNC). Appreciation is extended to the Central Histology Facility in Sacramento, CA, and to David Davies for photographic assistance.

\section{Author details}

'MIND Institute, University of California-Davis Medical Center, Sacramento, CA, USA. 'Department of Pediatrics, University of California-Davis Medical Center, Sacramento, CA, USA. ${ }^{3}$ Department of Pathology and Laboratory Medicine, University of California-Davis, School of Medicine, Sacramento, CA, USA. ${ }^{4}$ Graduate Program in Neuroscience, University of California-Davis, Davis, CA, USA. ${ }^{5}$ Department of Neurological Surgery, University of CaliforniaDavis, Davis, CA, USA. ${ }^{6}$ NeuroTherapeutic Research Institute, University of California-Davis, Davis, CA, USA. ${ }^{7}$ Department of Biochemistry and Molecular Medicine, University of California, School of Medicine, Davis, California, USA.
${ }^{8}$ Elwyn Fragile X Center, Elwyn, PA, USA. ${ }^{9}$ Department of Psychiatry and Behavioral Sciences, University of California, School of Medicine, Davis, California, USA.

\section{Authors' contributions}

CMG designed this study. CMG and LWJ performed the neuropathologic analysis of the brain tissues, and both participated in writing the manuscript. RFB and MRH designed the quantitative analyses of PC density, performed the quantitative measurements of $\mathrm{PC}$ number, and helped draft the manuscript. MRH confirmed the hippocampal pathologic findings, and designed and performed analyses of foliar width, blinded to patient history. LWJ performed and analyzed the calbindin IF analysis of the cerebellum. FT performed molecular analyses. RJH, JWA, MD and JS gathered clinical information and helped to write the manuscript. LWJ, PJH, RFB and RJH provided funding support, participated in study design and coordination, and helped to draft and revise the manuscript. CS helped to revise the manuscript. All authors read and approved the final manuscript.

\section{Competing interests}

$\mathrm{RJH}$ has received funding from Seaside Therapeutics, Roche, Forest, Johnson and Johnson, Curemark, Novartis and Neuropharm related to treatment studies in individuals with fragile X syndrome, FXTAS and/or autism. PJH and FT have submitted a patent application for a fragile $X$ screening method.

The authors have no financial conflicts.

Received: 24 April 2010 Accepted: 8 February 2011

Published: 8 February 2011

\section{References}

1. Belmonte MK, Bourgeron T: Fragile $X$ syndrome and autism at the intersection of genetic and neural networks. Nat Neurosci 2006, 9:1221-1225

2. Hagerman RJ, Rivera SM, Hagerman PJ: The fragile $X$ family of disorders: $A$ model for autism and targeted treatments. Curr Pediatr Rev 2008, 4:40-52.

3. Kaufmann WE, Cortell R, Kau AS, Bukelis I, Tierney E, Gray RM, Cox C, Capone GT, Stanard P: Autism spectrum disorder in fragile $X$ syndrome: communication, social interaction, and specific behaviors. Am J Med Genet 2004, 129A:225-234.

4. Rogers SJ, Wehner EA, Hagerman RJ: The behavioral phenotype in fragile $X$ : Symptoms of autism in very young children with fragile $X$ syndrome, idiopathic autism, and other developmental disorders. J Dev Behav Pediatr 2001, 22:409-417.

5. Hatton DD, Sideris J, Skinner M, Mankowski J, Bailey DB Jr, Roberts JE, Mirrett $P$ : Autistic behavior in children with fragile $X$ syndrome: Prevalence, stability, and the impact of FMRP. Am J Med Genet A 2006, 140:1804-1813.

6. Harris SW, Hessl D, Goodlin-Jones B, Ferranti J, Bacalman S, Barbato I, Tassone F, Hagerman PJ, Herman H, Hagerman RJ: Autism profiles of males with fragile X syndrome. Am J Ment Retard 2008, 113:427-438.

7. Bassell GJ, Warren ST: Fragile $X$ syndrome: loss of local mRNA regulation alters synaptic development and function. Neuron 2008, 60:201-214.

8. Pfeiffer BE, Huber KM: The state of synapses in fragile $X$ syndrome. Neuroscientist 2009, 15:549-567.

9. Qin M, Kang J, Burlin TV, Jiang C, Smith CB: Postadolescent changes in regional cerebral protein synthesis: an in vivo study in the FMR1 null mouse. J Neurosci 2005, 25:5087-5095.

10. Jin P, Warren ST: New insights into fragile $X$ syndrome: from molecules to neurobehaviors. Trends Biochem Sci 2003, 28:152-158.

11. Moro F, Pisano T, Bernardina BD, Polli R, Murgia A, Zoccante L, Darra F, Battaglia A, Pramparo T, Zuffardi O, Guerrini R: Periventricular heterotopia in fragile $X$ syndrome. Neurology 2006, 67:713-715.

12. Dunn H, Renpenning $H$, Gerrard J, Miller J, Tabata T, Federoff S: Mental retardation as a sex-linked defect. Am J Ment Defic 1963, 67:827-848.

13. Desai HB, Donat J, Shokeir MH, Munoz DG: Amyotrophic lateral sclerosis in a patient with fragile X syndrome. Neurology 1990, 40:378-380.

14. Richter JD, Klann E: Making synaptic plasticity and memory last: mechanisms of translational regulation. Genes Dev 2009, 23:1-11.

15. Lintas C, Persico AM: Autistic phenotypes and genetic testing: state-ofthe-art for the clinical geneticist. J Med Genet 2009, 46:1-8.

16. Darnell JC, Mostovetsky O, Darnell RB: FMRP RNA targets: identification and validation. Genes Brain Behav 2005, 4:341-349. 
17. Rosales-Reynoso MA, Ochoa-Hernandez AB, Barros-Nunez P: [Diseases caused by triplet expansion]. Rev Neurol 2009, 49:79-87.

18. Hagerman R, Hoem G, Hagerman P: Fragile $X$ and autism: Intertwined at the molecular level leading to targeted treatments. Mol Autism 2010, $1: 12$.

19. Darnell JC, van Dreische S, Zhang C, Mele A, Zang JB, Fak JJ, C S-W, Richter J, Darnell RB: HITS-CLIP Identifies Specific Neuronal mRNA Targets of Translational Repression by the Fragile X Mental Retardation Protein, FMRP [abstract]. Keystone Symposia; Snowbird, UT 2010, 56, Abstract \# 016

20. Luo Y, Shan G, Guo W, Smrt RD, Johnson EB, Li X, Pfeiffer RL, Szulwach KE, Duan R, Barkho BZ, Li W, Liu C, Jin P, Zhao X: Fragile $x$ mental retardation protein regulates proliferation and differentiation of adult neural stem/ progenitor cells. PLoS Genet 2010, 6:e1000898.

21. Reiss $A L$, Lee J, Freund L: Neuroanatomy of fragile $X$ syndrome: the temporal lobe. Neurology 1994, 44:1317-1324.

22. Kates WR, Abrams MT, Kaufmann WE, Breiter SN, Reiss AL: Reliability and validity of MRI measurement of the amygdala and hippocampus in children with fragile X syndrome. Psychiatry Res: Neuroimaging 1997, 75:31-48.

23. Gothelf D, Furfaro JA, Hoeft F, Eckert MA, Hall SS, O'Hara R, Erba HW, Ringel J, Hayashi KM, Patnaik S, Golianu B, Kraemer HC, Thompson PM, Piven J, Reiss AL: Neuroanatomy of fragile $X$ syndrome is associated with aberrant behavior and the fragile $\mathrm{X}$ mental retardation protein (FMRP). Ann Neurol 2008, 63:40-51.

24. Greco CM, Hagerman RJ, Tassone F, Chudley A, Del Bigio MR, Jacquemont $S$, Leehey $M$, Hagerman PJ: Neuronal intranuclear inclusions in a new cerebellar tremor/ataxia syndrome among fragile $\mathrm{X}$ carriers. Brain 2002, 125:1760-1771.

25. Whitney ER, Kemper TL, Rosene DL, Bauman ML, Blatt GJ: Calbindin-D28k is a more reliable marker of human Purkinje cells than standard Nissl stains: a stereological experiment. J Neurosci Methods 2008, 168:42-47.

26. Tassone F, Pan R, Amiri K, Taylor AK, Hagerman PJ: A rapid polymerase chain reaction-based screening method for identification of all expanded alleles of the fragile X (FMR1) gene in newborn and high-risk populations. J Mol Diagn 2008, 10:43-49.

27. Hessl D, Rivera SM, Reiss AL: The neuroanatomy and neuroendocrinology of fragile X syndrome. Ment Retard Dev Disabil Res Rev 2004, 10:17-24.

28. Jakala P, Hanninen T, Ryynanen M, Laakso M, Partanen K, Mannermaa A, Soininen H: Fragile-X: neuropsychological test performance, CGG triplet repeat lengths, and hippocampal volumes. J Clin Invest 1997, 100:331-338.

29. Sloviter RS, Kudrimoti HS, Laxer KD, Barbaro NM, Chan S, Hirsch L, Goodman RR, Pedley TA: "Tectonic" hippocampal malformations in patients with temporal lobe epilepsy. Epilepsy Res 2004, 59:123-153.

30. Reiss AL, Patel S, Kumar AJ, Freund L: Preliminary communication: neuroanatomical variations of the posterior fossa in men with the fragile X (Martin-Bell) syndrome. Am J Med Genet 1988, 31:407-414.

31. Holroyd S, Reiss AL, Bryan RN: Autistic features in Joubert syndrome: a genetic disorder with agenesis of the cerebellar vermis. Biol Psychiatry 1991, 29:287-294.

32. Mostofsky SH, Reiss AL, Lockhart P, Denckla MB: Evaluation of cerebellar size in attention-deficit hyperactivity disorder. J Child Neurol 1998, 13:434-439.

33. Nopoulos PC, Ceilley JW, Gailis EA, Andreasen NC: An MRI study of cerebellar vermis morphology in patients with schizophrenia: evidence in support of the cognitive dysmetria concept. Biol Psychiatry 1999, 46:703-711.

34. Eliez S, Schmitt JE, White CD, Wellis VG, Reiss AL: A quantitative MRI study of posterior fossa development in velocardiofacial syndrome. Biol Psychiatry 2001, 49:540-546.

35. Campbell LE, Daly E, Toal F, Stevens A, Azuma R, Catani M, Ng V, van Amelsvoort T, Chitnis X, Cutter W, Murphy DG, Murphy KC: Brain and behaviour in children with 22q11.2 deletion syndrome: a volumetric and voxel-based morphometry MRI study. Brain 2006, 129:1218-1228.

36. Amaral DG, Schumann CM, Nordahl CW: Neuroanatomy of autism. Trends Neurosci 2008, 31:137-145.

37. Kemper $T L$, Bauman M: Neuropathology of infantile autism. J Neuropathol Exp Neurol 1998, 57:645-652.

38. Webb SJ, Sparks BF, Friedman SD, Shaw DW, Giedd J, Dawson G, Dager SR: Cerebellar vermal volumes and behavioral correlates in children with autism spectrum disorder. Psychiatry Res 2009, 172:61-67.
39. Ichimiya T, Okubo Y, Suhara T, Sudo Y: Reduced volume of the cerebellar vermis in neuroleptic-naive schizophrenia. Biol Psychiatry 2001, 49:20-27.

40. Daskalakis ZJ, Christensen BK, Fitzgerald PB, Fountain SI, Chen R: Reduced cerebellar inhibition in schizophrenia: a preliminary study. Am J Psychiatry 2005, 162:1203-1205.

41. Mazzocco MM, Kates WR, Baumgardner TL, Freund LS, Reiss AL: Autistic behaviors among girls with fragile X syndrome. J Autism Dev Disord 1997, 27:415-435.

42. Arnold SE, Hyman BT, Van Hoesen GW, Damasio AR: Some cytoarchitectural abnormalities of the entorhinal cortex in schizophrenia. Arch Gen Psychiatry 1991, 48:625-632.

43. Arnold SE, Ruscheinsky DD, Han LY: Further evidence of abnormal cytoarchitecture of the entorhinal cortex in schizophrenia using spatial point pattern analyses. Biol Psychiatry 1997, 42:639-647.

44. Jakob H, Beckmann H: Prenatal developmental disturbances in the limbic allocortex in schizophrenics. J Neural Transm 1986, 65:303-326.

45. Wegiel J, Kuchna I, Nowicki K, Imaki H, Wegiel J, Marchi E, Ma SY, Chauhan A, Chauhan V, Bobrowicz TW, de Leon M, Louis LA, Cohen IL, London E, Brown WT, Wisniewski T: The neuropathology of autism: defects of neurogenesis and neuronal migration, and dysplastic changes. Acta Neuropathol 2010, 119:755-770.

46. Bailey A, Luthert P, Dean A, Harding B, Janota I, Montgomery M, Rutter M, Lantos P: A clinicopathological study of autism. Brain 1998, 121(Pt 5):889-905.

47. Bernstein HG, Krell D, Baumann B, Danos P, Falkai P, Diekmann S, Henning $H$, Bogerts B: Morphometric studies of the entorhinal cortex in neuropsychiatric patients and controls: clusters of heterotopically displaced lamina II neurons are not indicative of schizophrenia. Schizophr Res 1998, 33:125-132.

48. Akil M, Lewis DA: Cytoarchitecture of the entorhinal cortex in schizophrenia. Am J Psychiatry 1997, 154:1010-1012.

49. Krimer LS, Herman MM, Saunders RC, Boyd JC, Hyde TM, Carter JM, Kleinman JE, Weinberger DR: A qualitative and quantitative analysis of the entorhinal cortex in schizophrenia. Cereb Cortex 1997, 7:732-739.

50. Fatemi SH, Kneeland RE, Liesch SB, Folsom TD: Fragile X mental retardation protein levels are decreased in major psychiatric disorders. Schizophr Res 2010, 124:246-7.

51. Fatemi SH, Folsom TD: The role of fragile $X$ mental retardation protein in major mental disorders. Neuropharmacology 2010.

52. Oguro-Ando A, Bomar J, Abrahams B, Herman E, Werling D, Roesensweig C, Nishimura Y, Dong H, DH G: Functional analysis of CYFIP as an Autism Candidate Gene using a BAC transgenic model [abstract]. Keystone Symposia: Towards Defining the Pathophysiology of Autistic behavior; April 1115; Snowbird, Utah, USA 2010, 116, Abstract \# 201.

53. Napoli I, Mercaldo V, Boyl PP, Eleuteri B, Zalfa F, De Rubeis S, Di Marino D, Mohr E, Massimi M, Falconi M, Witke W, Costa-Mattioli M, Sonenberg N, Achsel $T$, Bagni $C$ : The fragile $X$ syndrome protein represses activitydependent translation through CYFIP1, a new 4E-BP. Cell 2008, 134:1042-1054

54. Nowicki ST, Tassone F, Ono MY, Ferranti J, Croquette MF, Goodlin-Jones B, Hagerman RJ: The Prader-Willi phenotype of fragile X syndrome. J Dev Behav Pediatr 2007, 28:133-138.

55. D'Hulst C, Heulens I, Brouwer JR, Willemsen R, De Geest N, Reeve SP, De Deyn PP, Hassan BA, Kooy RF: Expression of the GABAergic system in animal models for fragile $X$ syndrome and fragile $X$ associated tremor/ ataxia syndrome (FXTAS). Brain Research 2009, 1253:176-183.

56. Selby L, Zhang C, Sun QQ: Major defects in neocortical GABAergic inhibitory circuits in mice lacking the fragile $X$ mental retardation protein. Neurosci Lett 2007, 412:227-232.

57. Utari A, Adams E, Berry-Kravis E, Chavez A, Scaggs F, Ngotran L, Boyd A, Hessl D, Gane LW, Tassone F, Tartaglia N, Leehey MA, Hagerman RJ: Aging in fragile X syndrome. J Neurodev Disord 2010, 2:70-76.

58. Eadie B, Christie B: Abnormal neurogenesis in the hippocampus of a mouse model of fragile $X$ syndromes. Clin Invest Med 2007, 30(Suppl): S80.

59. Rudelli RD, Jenkins EC, Wisniewski K, Moretz R, Byrne J, Brown WT: Testicular size in fetal fragile $X$ syndrome. Lancet 1983, 1:1221-1222.

60. Rudelli RD, Brown WT, Wisniewski K, Jenkins EC, Laure-Kamionowska M, Connell F, Wisniewski HM: Adult fragile $X$ syndrome. Cliniconeuropathologic findings. Acta Neuropathologica 1985, 67:289-295. 
61. Hinton VJ, Brown WT, Wisniewski K, Rudelli RD: Analysis of neocortex in three males with the fragile X syndrome. Am J Med Genet 1991 41:289-294.

62. Wisniewski KE, Segan SM, Miezejeski CM, Sersen EA, Rudelli RD: The Fra(X) syndrome: neurological, electrophysiological, and neuropathological abnormalities. Am J Med Genet 1991, 38:476-480.

63. Sabaratnam M: Pathological and neuropathological findings in two males with fragile X syndrome. J Intellect Disabil Res 2000, 44:81-85.

64. Irwin SA, Patel B, Idupulapati M, Harris JB, Crisostomo RA, Larsen BP, Kooy F, Willems PJ, Cras P, Kozlowski PB, Swain RA, Weiler IJ, Greenough WT:

Abnormal dendritic spine characteristics in the temporal and visual cortices of patients with fragile-X syndrome: a quantitative examination. Am J Med Genet 2001, 98:161-167.

doi:10.1186/2040-2392-2-2

Cite this article as: Greco et al:: Neuropathologic features in the hippocampus and cerebellum of three older men with fragile $X$ syndrome. Molecular Autism 2011 2:2.

\section{Submit your next manuscript to BioMed Central} and take full advantage of:

- Convenient online submission

- Thorough peer review

- No space constraints or color figure charges

- Immediate publication on acceptance

- Inclusion in PubMed, CAS, Scopus and Google Scholar

- Research which is freely available for redistribution

Submit your manuscript at www.biomedcentral.com/submit
C Biomed Central 